\title{
Formation and transformation of volatile nanoparticles from a diesel engine during exhaust dilution
}

\author{
LI XinLing* \& HUANG Zhen \\ Key Laboratory of Power Machinery and Engineering Education Ministry, Shanghai Jiao Tong University, Shanghai 200240, China
}

Received September 1, 2011; accepted November 3, 2011

\begin{abstract}
A classic $\mathrm{H}_{2} \mathrm{SO}_{4}-\mathrm{H}_{2} \mathrm{O}$ binary homogeneous nucleation model coupled to an aerosol dynamics model, suitable for studying the formation and transformation of volatile nanoparticles (VNPs) during diesel engine exhaust dilution, has been developed. Using the $\mathrm{H}_{2} \mathrm{SO}_{4}-\mathrm{H}_{2} \mathrm{O}$ binary homogeneous nucleation model, the nucleation ratio and molecular cluster size were calculated. The effect of aerosol dynamic processes on VNP number size distributions was studied. The effects of fuel sulfur content (FSC) and sampling conditions in the laboratory on VNP number size distributions were also calculated. Our simulations demonstrated that nucleation increased the cluster number concentration and that FSC, temperature and humidity significantly affected the nucleation ratio and molecular cluster size. Coagulation promoted the evolution of cluster-particle size distributions from monodisperse to polydisperse. Soot present in the exhaust can suppress the formation of VNPs. FSC and sampling conditions, like the primary dilution temperature, the primary dilution relative humidity, residence time and the primary dilution ratio have significant effects on VNP number size distributions.
\end{abstract}

diesel engine exhaust, volatile nanoparticles, $\mathrm{H}_{2} \mathrm{SO}_{4}-\mathrm{H}_{2} \mathrm{O}$ binary homogeneous nucleation, aerosol dynamic processes

Citation: $\quad$ Li X L, Huang Z. Formation and transformation of volatile nanoparticles from a diesel engine during exhaust dilution. Chin Sci Bull, 2012, 57: 948-954, doi: $10.1007 / \mathrm{s} 11434-011-4927-8$

Volatile nanoparticle (VNP) pollution in the atmosphere has received increased interest because of a strong association with human lung cancer, based on epidemiological studies [1]. With increasing vehicle use in large cities, vehicle emissions are becoming a major source of VNPs in urban environments [2]. The presence of sulfuric acid, water vapor and numerous hydrocarbon species in vehicular emissions, especially diesel emissions, results in complex physical/ chemical processes that affect the formation and transformation of VNPs during exhaust dilution [3]. Several groups have conducted measurements on the formation and transformation of VNPs from vehicle exhaust [4-6]. VNP number size distributions are nonlinear and highly sensitive to the temperature, humidity and dilution ratio during the dilution process. Recently, theoretical studies on VNPs in diesel engine exhaust have been conducted $[7,8]$. These studies largely focused on the evolution of VNPs in the atmosphere,

*Corresponding author (email: 1xl@ @jtu.edu.cn) leaving many questions about the mechanisms driving the formation and transformation of VNPs. Further research in this area is necessary.

In this study, a classic $\mathrm{H}_{2} \mathrm{SO}_{4}-\mathrm{H}_{2} \mathrm{O}$ binary homogeneous nucleation model coupled to an aerosol dynamics model is presented. The work in this paper includes: (1) the nucleation ratio and molecular cluster size based on binary $\mathrm{H}_{2} \mathrm{SO}_{4}^{-}$ $\mathrm{H}_{2} \mathrm{O}$ homogeneous nucleation theory, (2) the effect of the aerosol dynamic processes on VNP number size distributions and (3) the effects of fuel sulfur content (FSC) and sampling conditions in the laboratory on VNP number size distributions. The experimental results were then compared with the modeling results.

\section{Modeling methods}

The evolution of VNP number size distributions, accounting for nucleation, coagulation and condensation/evaporation, is 
represented by the following discrete dynamic equation [9]:

$$
\begin{aligned}
\frac{\mathrm{d} N_{k}}{\mathrm{~d} t}= & \underbrace{J(t) \delta_{k}}_{\text {nucleation }}+\underbrace{\frac{1}{2} \sum_{j=1}^{k-1} \beta_{k-j, j} N_{k-j, j} N_{j}-N_{k} \sum_{j=1}^{\infty} \beta_{k, j} N_{j}}_{\text {coagualtion }} \\
& +\underbrace{\beta_{1, k-1} N_{1} N_{k-1}-\beta_{1, k} N_{1} N_{k}}_{\text {condensation/evaporation }},
\end{aligned}
$$

where $N_{k}$ is the time $(t)$-dependent number concentration of VNPs of volume $v_{k}, \beta_{k, j}$ is the coagulation kernel of two colliding particles, $N_{1}$ is the semi-volatile compounds molecular number concentration, and $\delta_{k}$ is the size-splitting factor.

Only sulfuric acid is likely to be supersaturated enough for homogeneous nucleation in dilute engine exhaust. For example, in a $\mathrm{H}_{2} \mathrm{SO}_{4}-\mathrm{H}_{2} \mathrm{O}$ binary mixture, at a temperature of $298 \mathrm{~K}$ and a relative humidity of $50 \%$, the partial pressure of $\mathrm{H}_{2} \mathrm{SO}_{4}$ is greater than $1.3 \times 10^{-8} \mathrm{~Pa}$. At this pressure, rapid self-nucleation would take place, suggesting that homogeneous nucleation could still be possible under atmospheric conditions when the relative humidity is below $50 \%$, even if the concentration of $\mathrm{H}_{2} \mathrm{SO}_{4}$ was extremely low. $\mathrm{SO}_{3}$ and sulfuric acid vapor are produced during combustion by the oxidation of sulfur present in diesel fuel or lubricating oil. Sulfuric acid and water undergo rapid binary nucleation, even at extremely low sulfuric acid vapor concentrations. Therefore, the $\mathrm{H}_{2} \mathrm{SO}_{4}-\mathrm{H}_{2} \mathrm{O}$ binary homogenous nucleation process plays an important role in the formation and transformation of VNPs emitted from diesel engines during exhaust dilution [10].

The $\mathrm{H}_{2} \mathrm{SO}_{4}$ hydrate (embryo) formation rate is predicted by the nucleation equation [11]:

$$
J=C \exp \left(-\Delta G^{*} / k_{b} T\right)
$$

where $C$ is the frequency factor, $k_{b}$ is the Boltzmann constant, $T$ is the temperature and $\Delta G^{*}$ is the minimum free energy required to form an embryo. The free energy of formation for an embryo of arbitrary size and composition is defined as [12]:

$$
\Delta G=-n_{a} k T \ln \frac{A_{a g}}{A_{a l}}-n_{w} k T \ln \frac{A_{w g}}{A_{w l}}+4 \pi r^{2} \sigma,
$$

and

$$
\begin{gathered}
A_{a g}=\frac{p_{a}}{p_{a s}}=\frac{R T\left[\mathrm{H}_{2} \mathrm{SO}_{4}\right]}{p_{a s}}, \\
A_{a l}=\frac{p_{a, s o l}}{p_{a s}}, \\
A_{w g}=\frac{p_{w}}{p_{w s}}=\frac{R T\left[\mathrm{H}_{2} \mathrm{O}\right]}{p_{w s}}, \\
A_{w l}=\frac{p_{w, s o l}}{p_{w s}},
\end{gathered}
$$

where $A_{\mathrm{ag}}$ and $A_{\mathrm{al}}$ are the acid activity in the gas and liquid phases, respectively, $A_{\mathrm{wg}}$ and $A_{\mathrm{wl}}$ are the water activity in the gas and liquid phases, respectively, $p_{a}$ and $p_{w}$ are the partial vapor pressures of the acid and water vapors on a flat surface of a pure substance, respectively, $p_{a, s o l}$ and $p_{w, s o l}$ are the partial vapor pressures of the acid and water vapors over a flat surface of a solution, respectively, $r$ is the radius of the particle, $n_{a}$ and $n_{w}$ are numbers of sulfuric acid and water molecules in the molecular cluster, respectively, and $\sigma$ is the surface tension of the cluster.

The minimum free energy, $\Delta G^{*}$, and the radius of the critical cluster, $r^{*}$, can be determined using the following two equations:

$$
\left(\frac{\partial \Delta G}{\partial n_{a}}\right)_{n}=\left(\frac{\partial \Delta G}{\partial n_{w}}\right)_{n}=0,
$$

and

$$
\begin{gathered}
r^{*}=\frac{2 \sigma V}{k T\left(x_{a} \ln \frac{A_{a g}}{A_{a l}}+x_{w} \ln \frac{A_{w g}}{A_{w l}}\right)}, \\
\Delta G^{*}=\frac{4}{3} \pi r^{* 2} \sigma,
\end{gathered}
$$

where $x_{a}$ and $x_{w}$ are the mole fraction of sulfuric acid and water molecules in the molecular cluster, respectively.

\section{Apparatus and baseline parameters}

The experiments were carried out using a medium-duty diesel engine on an engine rig at a constant engine load and a speed of $60 \%$ with $2200 \mathrm{r} / \mathrm{min}$. All tests were run using standard diesel fuel with a sulfur content of $0.04 \%$. The effect of fuel sulfur content on exhaust VNP emissions was studied by comparing VNP emissions from gas-to-liquid fuel and standard diesel fuel. If the sulfur to sulfuric acid conversion efficiency was $4 \%[13,14]$, the sulfuric acid molecular number concentration can be determined from mass conservation. Sulfur contribution from lubricating oil was neglected in this study. We also assumed that all hydrocarbons in the exhaust were $\mathrm{C} 16$ species. C16 hydrocarbon molecular concentrations were determined as reported in [14].

A two-stage sampling and dilution system was used. A full description of the sampling system used has previously been reported $[15,16]$. Briefly, the sampling process involved drawing a fraction of the exhaust from the exhaust manifold into the primary dilution tunnel where it was mixed with a constant flow of clean ambient air drawn through a high-flow HEPA filter using an air pump. A valve was used in the sampling line to control the fraction of the exhaust passing through the sampling line to control the dilution ratio. Silica gel was used to remove water vapor to 
reduce the humidity as much as possible. The humidity in the tunnel was controlled by introducing water vapor and the temperature was controlled by introducing heated air with air heater. A secondary dilution system was used to further decrease particle concentrations to the concentration range of the instrument. Particle size distributions were measured using a TSI 3034 SMPS (scanning mobility particle sizer) and particle number concentrations were measured using a TSI 3010 CPC (condensation particle counter).

Four sampling parameters, the primary dilution temperature (PDT), the primary dilution relative humidity $(\mathrm{PRH})$, residence time (RT) and the primary dilution ratio (PDR), were independently controlled. The key input parameters used in the simulations, for both the baseline scenario and the variation range, are provided in Table 1 . Three consecutive SMPS scans were conducted over a period of $10 \mathrm{~min}$ after each parameter change. The data were obtained during the last 3 min after each parameter change.

\section{Results and discussion}

\subsection{Nucleation ratio and molecular cluster size from $\mathrm{H}_{2} \mathrm{SO}_{4}-\mathrm{H}_{2} \mathrm{O}$ binary nucleation theory}

From $\mathrm{H}_{2} \mathrm{SO}_{4}-\mathrm{H}_{2} \mathrm{O}$ binary homogeneous nucleation theory, VNPs originate by growth of molecular clusters formed through $\mathrm{H}_{2} \mathrm{SO}_{4}-\mathrm{H}_{2} \mathrm{O}$ binary homogeneous nucleation. This means that nucleation plays a significant role in VNP formation during exhaust dilution. The molecular cluster nucleation ratio and size are two important factors in the nucleation process. The nucleation rate is defined as the number of molecular clusters formed per unit of time and the increase in the number of molecular clusters per unit of time.

Figure 1(a) shows the effects of the FSC, temperature and relative humidity on molecular cluster size. Molecular clusters of approximately 1-2 $\mathrm{nm}$ in diameter were formed through $\mathrm{H}_{2} \mathrm{SO}_{4}-\mathrm{H}_{2} \mathrm{O}$ binary homogeneous nucleation. The cluster size exponentially decreased with increasing FSC. The cluster size sharply decreased as the FSC increased from $0.001-0.02 \%$. The cluster size decreased with increased relative humidity. The effect of relative humidity on cluster size was significant at high temperatures (e.g., $55^{\circ} \mathrm{C}$ ) and weak at low temperatures (e.g., $25^{\circ} \mathrm{C}$ ). The cluster size increased with increasing temperature.

Figure 1(b) shows the effect of the FSC, temperature and relative humidity on the molecular cluster nucleation rate. The nucleation rate increased with increasing FSC and relative humidity. Relative humidity had a significant effect on the nucleation rate at high temperatures (e.g., $55^{\circ} \mathrm{C}$ ) and a weak effect at low temperatures (e.g., $25^{\circ} \mathrm{C}$ ). At a FSC of $0.05 \%$, the nucleation rate increased 11 orders of magnitude when the relative humidity was increased from $10-100 \%$ at $55^{\circ} \mathrm{C}$, while the nucleation rate increased only one order of magnitude when the relative humidity was increased from $10-100 \%$ at $25^{\circ} \mathrm{C}$. The nucleation rate significantly in creased with deceasing temperature. For example, at a FSC of $0.05 \%$, the nucleation rate at $25^{\circ} \mathrm{C}$ was $2-12$ orders of magnitude larger than at $55^{\circ} \mathrm{C}$ at the same relative humidity.

\subsection{Effect of the aerosol dynamic processes on VNP number size distributions}

Figure 2 present the effect of the aerosol dynamic processes on VNP number size distributions as time $(t)$ elapsed. Table 2 presents the number concentration of VNPs larger than $3 \mathrm{~nm}$ in diameter $\left(N_{d>3} \mathrm{~nm}\right)$, geometric number mean diameter $\left(D G N_{d>3 \mathrm{~nm}}\right)$ and geometric standard deviation $\left(\sigma_{d>3 \mathrm{~nm}}\right)$ as time elapsed. Figure 2(a) shows that the $D G N_{d>3 \mathrm{~nm}}$ increased from $3.2 \mathrm{~nm}$ at $t=0.01 \mathrm{~s}$ to $7.4 \mathrm{~nm}$ at $t=2 \mathrm{~s}$ and $\sigma_{d>3 \mathrm{~nm}}$ increased from 1.01-1.58 during the same time period, indicating that the VNP number size distributions changed from monodisperse to polydisperse. Particle diameters increased as time elapsed, resulting from coagulation. Figure 2(b) shows the effect of hydrocarbon condensation (we assumed that the $\mathrm{C} 16$ molecular concentration in the diluted exhaust was $10^{14} \mathrm{~cm}^{-3}$ ) on the evolution of VNP size distributions. Figure 2(b) shows that condensation promotes the evolution of VNPs. For example, the $D G N_{d>3} \mathrm{~nm}$ increased from $3.7 \mathrm{~nm}$ at $t=0.01 \mathrm{~s}$ to $21.5 \mathrm{~nm}$ at $t=2 \mathrm{~s}$. Figure 2(c) shows the effect of soot scavenging (assuming a soot particle concentration of $10^{7} \mathrm{~cm}^{-3}$, a $D G N$ of $130 \mathrm{~nm}$ and a $\sigma$ of 1.8). In comparison with the soot free case, a distinct shift in the VNP number size distributions towards smaller diameters and a decrease in $N_{d>3 \mathrm{~nm}}$ was observed. It is likely that sulfuric acid and semi-volatile hydrocarbon vapors condense on the surface of soot particles, suppressing the formation/growth of VNPs. This result is consistent with

Table 1 Parameter used in the baseline case and the variation range

\begin{tabular}{lcc}
\hline \multicolumn{1}{c}{ Parameter } & Baseline case & Simulation ranges \\
\hline Fuel sulfur content FSC $(\%)$ & 0.04 & $0.001-0.1$ \\
Primary dilution temperature RDT $\left({ }^{\circ} \mathrm{C}\right)$ & 32 & $25-55$ \\
Primary dilution humidity $R H(\%)$ & 60 & $10-100$ \\
Primary residence time $R T(\mathrm{~s})$ & 0.5 & 0.04 \\
Primary dilution ratio PDR & 15 & $42,43,56$ \\
\hline
\end{tabular}



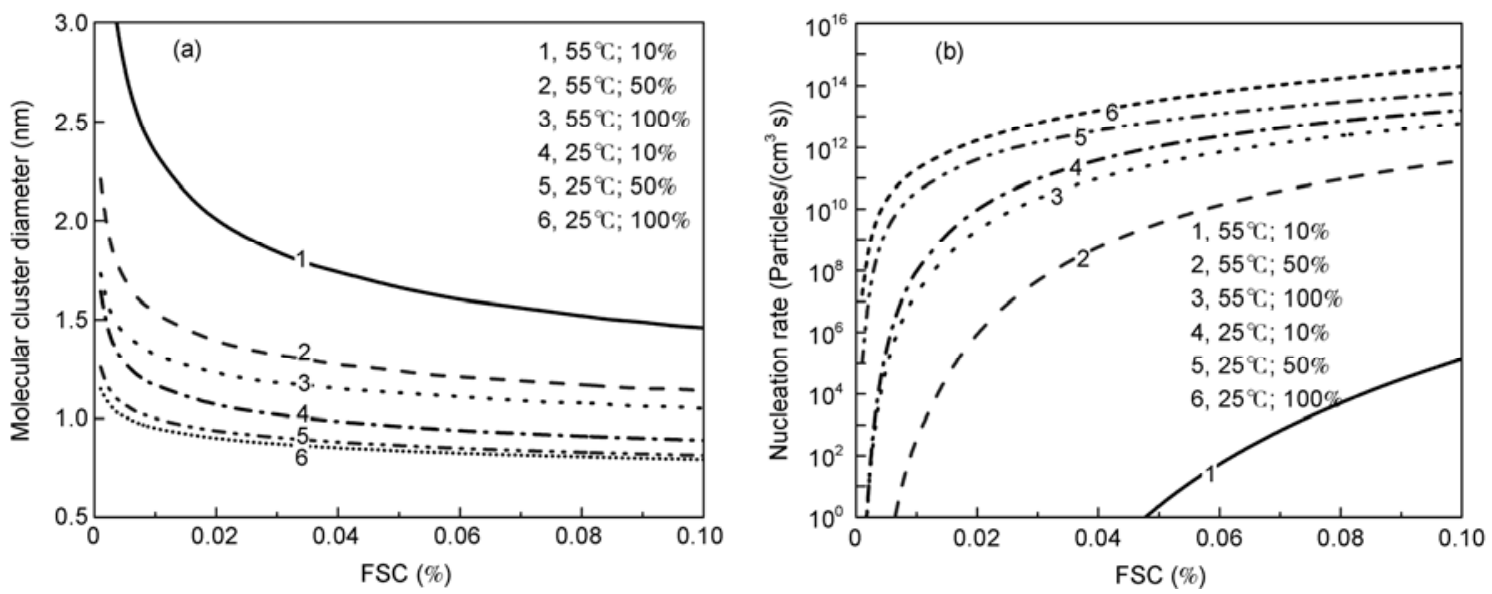

Figure 1 Molecular cluster size (a) and nucleation ratio (b) from $\mathrm{H}_{2} \mathrm{SO}_{4}-\mathrm{H}_{2} \mathrm{O}$ binary nucleation theory.
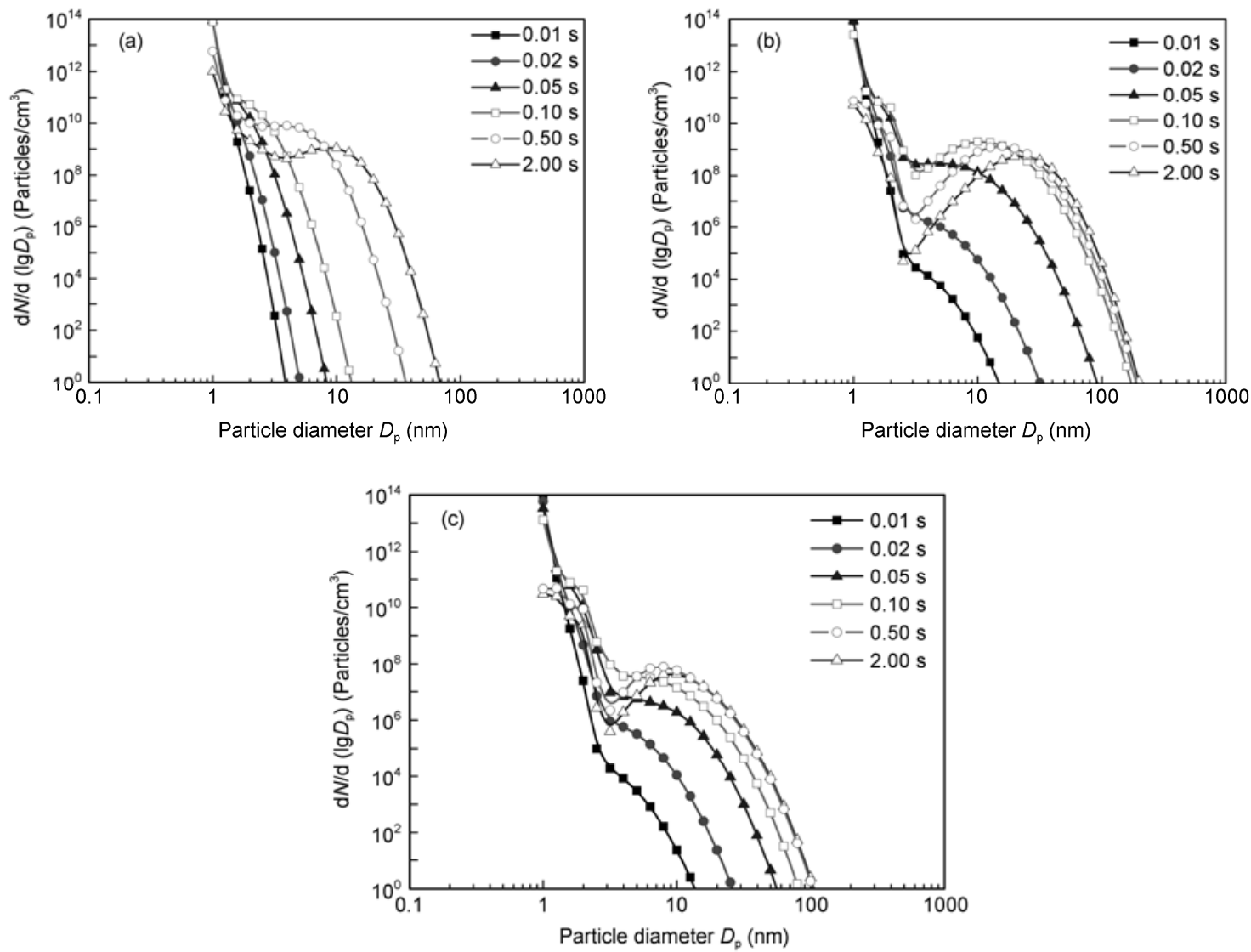

Figure 2 Effect of the aerosol dynamic processes (a) Nuc. + coag., (b) Nuc. + coag + cond. (soot free) and (c) Nuc. + coag. + cond. (with soot) on VNP number size distributions as time elapsed.

previous measurements that indicated a reduction in soot concentrations from modern engines or use of a particle filter lead to an increase in VNP emissions [14].

\subsection{Effect of FSC and sampling conditions on VNP number size distributions}

Figures 3-7 present the calculated VNP number size distri- butions under different FSC and sampling conditions, accounting for nucleation, coagulation and condensation/ evaporation, using eq. (1). Acceptable agreement between the calculated and observed VNP number size distributions was obtained, as shown in Figures 3-7. This suggests that the model can accurately simulate the formation and transformation of VNPs during exhaust dilution. Discrepancies in the VNP number size distributions likely result from 
Table 2 Effect of the aerosol dynamics on the VNP number size distribution parameters as time elapsed

\begin{tabular}{|c|c|c|c|c|c|c|c|}
\hline \multicolumn{2}{|c|}{ Residence time (s) } & 0.01 & 0.02 & 0.05 & 0.1 & 0.5 & 2.0 \\
\hline \multirow{3}{*}{ Nuc. + coag. } & $N_{d>3 \mathrm{~nm}}\left(\right.$ Particles $\left./ \mathrm{cm}^{3}\right)$ & $3.5 \times 10^{2}$ & $1.0 \times 10^{5}$ & $1.1 \times 10^{8}$ & $5.2 \times 10^{9}$ & $2.8 \times 10^{10}$ & $5.8 \times 10^{9}$ \\
\hline & $D G N_{d>3 \mathrm{~nm}}(\mathrm{~nm})$ & 3.2 & 3.2 & 3.2 & 3.3 & 4.4 & 7.4 \\
\hline & $\sigma_{d>3 \mathrm{~nm}}$ & 1.01 & 1.02 & 1.04 & 1.08 & 1.32 & 1.58 \\
\hline \multirow{3}{*}{$\begin{array}{l}\text { Nuc. + coag. + cond. } \\
\text { (soot free) }\end{array}$} & $N_{d>3 \mathrm{~nm}}\left(\right.$ Particles $\left./ \mathrm{cm}^{3}\right)$ & $5.0 \times 10^{4}$ & $6.0 \times 10^{6}$ & $1.6 \times 10^{9}$ & $1.0 \times 10^{10}$ & $6.2 \times 10^{10}$ & $2.5 \times 10^{9}$ \\
\hline & $D G N_{d>3 \mathrm{~nm}}(\mathrm{~nm})$ & 3.7 & 4.1 & 5.6 & 10.7 & 15.2 & 21.5 \\
\hline & $\sigma_{d>3 \mathrm{~nm}}$ & 1.22 & 1.32 & 1.54 & 1.57 & 1.51 & 1.50 \\
\hline \multirow{2}{*}{ Nuc. + coag. + cond. (with soot) } & $N_{d>3 \mathrm{~nm}}\left(\right.$ Particles $\left./ \mathrm{cm}^{3}\right)$ & $3.1 \times 10^{4}$ & $2.0 \times 10^{6}$ & $3.2 \times 10^{7}$ & $2.4 \times 10^{8}$ & $3.0 \times 10^{8}$ & $1.7 \times 10^{8}$ \\
\hline & $\sigma_{d>3 \mathrm{~nm}}$ & 1.21 & 1.29 & 1.50 & 1.55 & 1.45 & 1.44 \\
\hline
\end{tabular}

neglecting the effects of sulfates, nitrates, metals and semivolatile organic species in the exhaust.

FSC had a large effect on the VNP number size distributions, as shown in Figure 3. VNP number concentrations increased with increasing FSC. The calculated data were in agreement with the experimental data. Increased VNP and total particle number concentrations with increasing FSC were also observed previously [17]. It was shown that particles increased in diameter when the FSC increased from $0.06 \%-0.2 \%$. This is because increased FSC promotes the formation of sulfur trioxide, and increases the formation rate of molecular clusters. Larger VNPs are produced when there are more molecular clusters present in the exhaust through coagulation and condensation processes.

The PDT also plays an important role in the formation
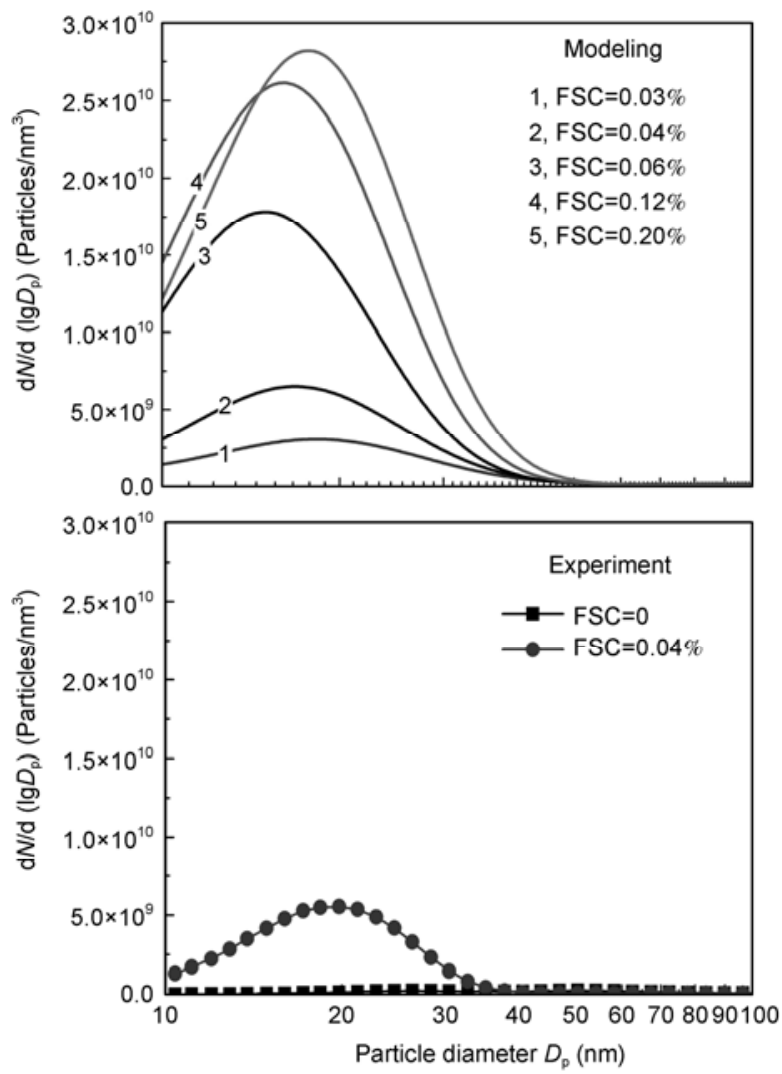

Figure 3 Effect of FSC on VNP number size distributions. and transformation of VNPs, as shown in Figure 4. When the PDT was greater than $50^{\circ} \mathrm{C}$, the $\mathrm{H}_{2} \mathrm{SO}_{4}-\mathrm{H}_{2} \mathrm{O}$ nucleation rate was very low, leading to little VNP production. VNP number concentrations significantly increased when the PDT decreased from $50-30^{\circ} \mathrm{C}$. This is because the partial vapor pressures of sulfuric acid, water and semi-volatile hydrocarbon species involved in the formation of VNPs increased with decreasing PDTs, enhancing nucleation and condensation.

Figure 5 illustrates the effect of the PRH on the VNP number size distributions. The VNP number concentrations significantly increased when the PRH increased from 20-100\%. The calculated data were in agreement with the measurements. A similar result was observed by Mathis et al. [18]. As the PRH increased in the diluted exhaust, the

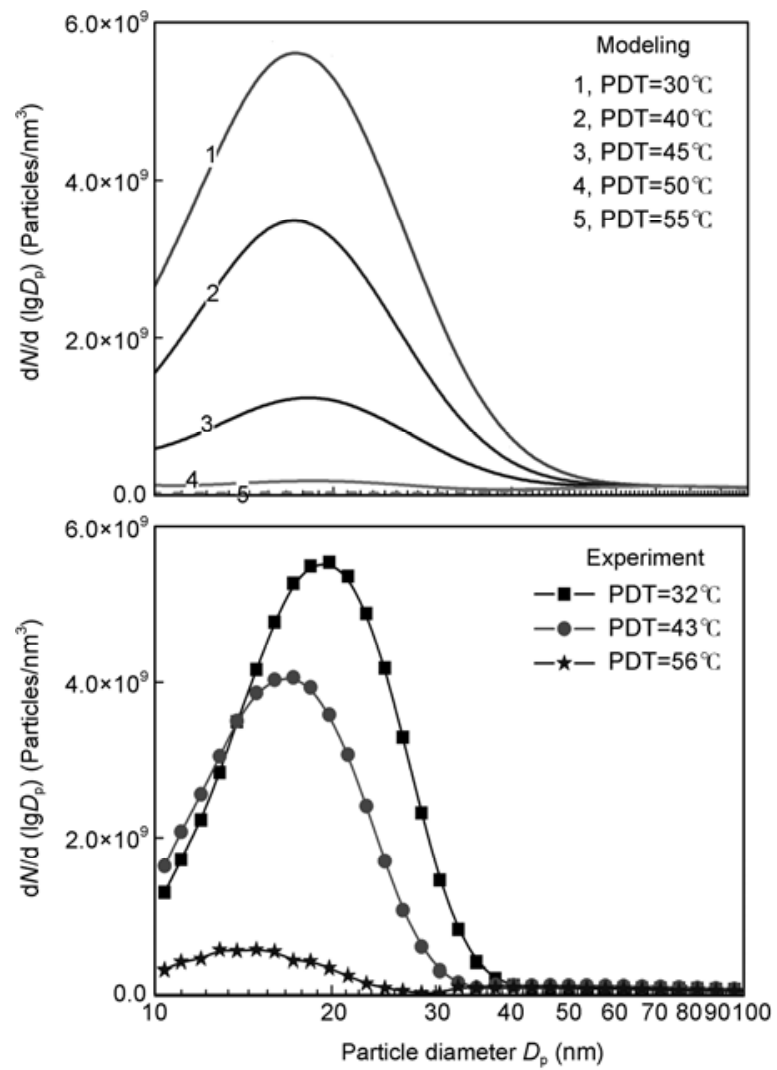

Figure 4 Effect of the PDT on VNP number size distributions. 

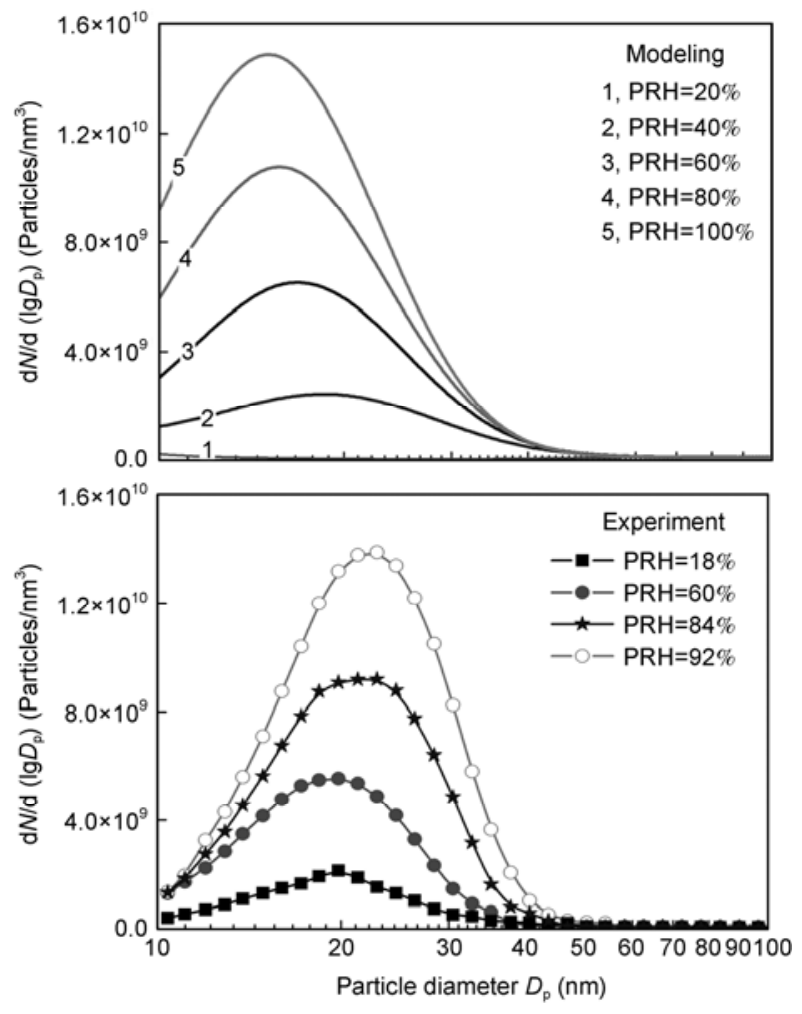

Figure 5 Effect of the PRH on VNP number size distributions.
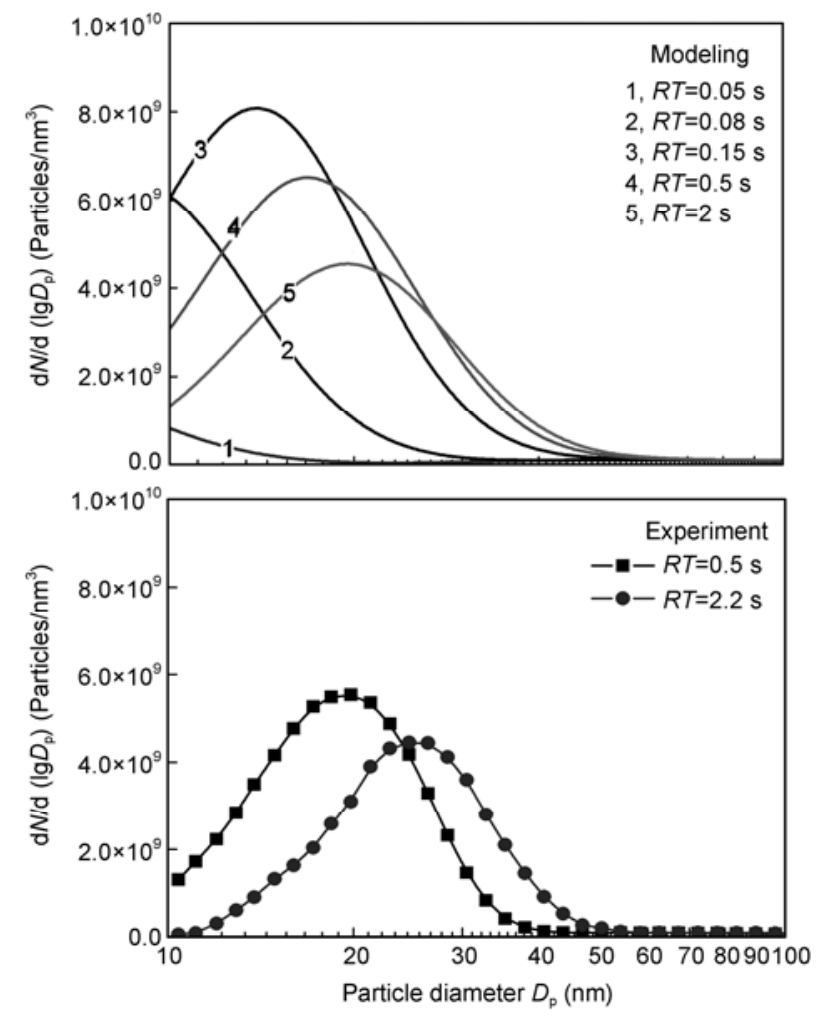

Figure 6 Effect of the $R T$ on VNP number size distributions.

partial vapor pressures of the water molecules significantly increased, which increased the molecular cluster nucleation rate, as shown in Figure 1(b). An increase of the water molecule saturation vapor pressure can decrease cluster size (see Figure 1(a)), shifting the particle sizes to smaller diameters as the PRH increases from 40\%-100\%.

The effect of RT on VNP size distributions is presented in Figure 6. Variations in the VNP size distributions with increasing RT involved two stages. At RTs less than $0.15 \mathrm{~s}$, the particles shifted to larger diameters and VNP number concentrations increased with increasing RT. At RTs greater than $0.15 \mathrm{~s}$, the particles shifted to even larger diameters, but the VNP number concentrations decreased with increasing RT. On one hand, the nucleation process promotes the formation of VNPs as RT increases, VNPs shift towards larger sizes by the coagulation and condensation. One the other hand, VNP number concentrations reduce by the coagulation process. These results indicate that when the RT is less than $0.15 \mathrm{~s}$, nucleation processes are dominant and the VNP number concentrations significantly increase. When the RT is greater than $0.15 \mathrm{~s}$, the coagulation process is dominant and VNP number concentrations decrease. These results are in agreement with the measurements.

VNP number concentrations were highly sensitive to the PDR, as shown in Figure 7. The highest concentrations of VNPs were observed between PDRs of 12-15, according to the measurements. A similar result was observed by Mathis et al. [18]. The effect of the PDR on VNP size distributions can be explained as follows. When the PDR decreases from 12 to 4 , VNP number concentrations significantly decreased

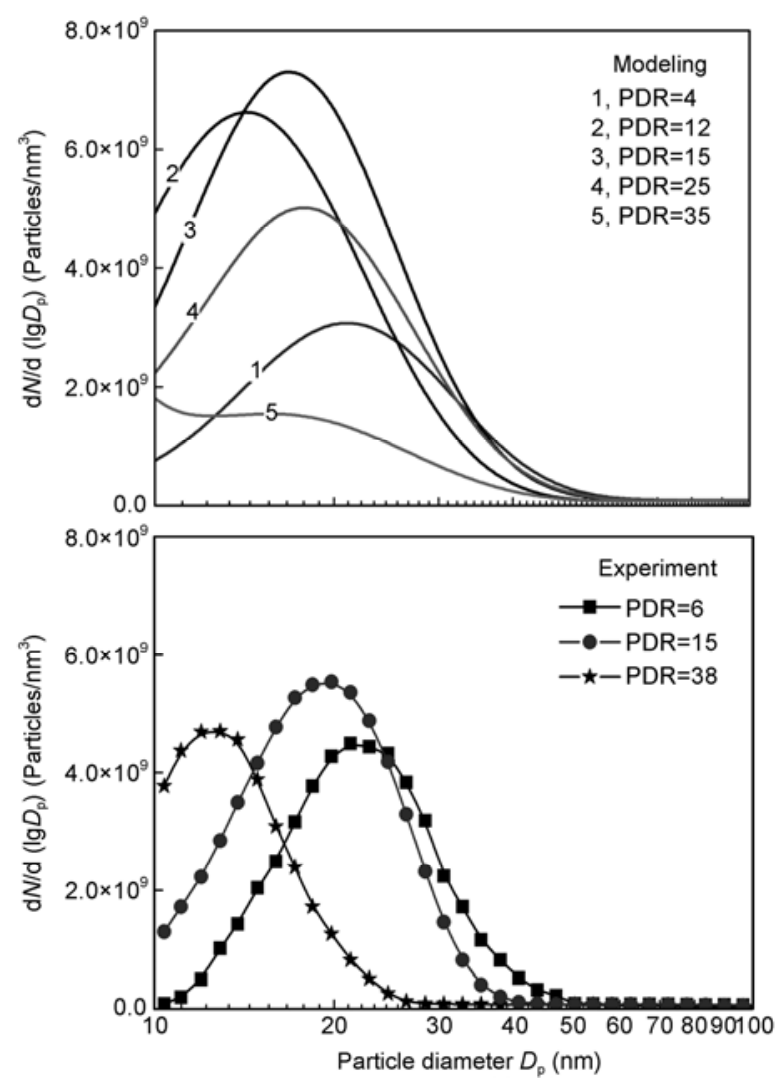

Figure 7 Effect of the PDR on VNP number size distributions. 
because the soot concentration increased, suppressing the formation of VNPs. In comparison with particles at a PDR of 12 , the particles at a PDR of 4 shift to larger diameters due to the increased partial vapor pressures of species involved in the formation and growth of VNPs through condensation. VNP number concentrations significantly increased and the particles shifted to larger diameters when the PDR increased from 12-15. This may be the result of the decreasing temperature from a high PDR leading to an increase in the intensity of the nucleation process, which would increase the VNP number concentration. The coagulation of VNPs at high concentrations promotes a shift to larger particle diameters. When the PDR increased from 15-35, the partial vapor pressures of the species involved in the formation and growth of VNPs decreased, resulting in a weakening of the dynamic processes and a decrease in VNP number concentrations.

\section{Conclusions}

Molecular clusters, approximately 1-2 $\mathrm{nm}$ in diameter, were formed through $\mathrm{H}_{2} \mathrm{SO}_{4}-\mathrm{H}_{2} \mathrm{O}$ binary homogeneous nucleation. The cluster size exponentially decreased with increasing FSC. The cluster size sharply decreased as the FSC increased from $0.001 \%-0.02 \%$. The effect of FSC on molecular cluster size was more significant at low FSC. The effect of relative humidity on cluster size was more significant at high temperatures. Cluster size increased with increasing temperature. Higher nucleation rates were observed at high FSC and high relative humidity. The effect of relative humidity on the nucleation rate was more significant at high temperatures.

Molecular clusters formed through $\mathrm{H}_{2} \mathrm{SO}_{4}-\mathrm{H}_{2} \mathrm{O}$ binary homogeneous nucleation changed from monodisperse to polydisperse and the particle diameters increased as time elapsed as a result of coagulation. The condensation process promotes the evolution of the VNPs. Semi-volatile hydrocarbon species condensed on the surface of soot particles, suppressing the growth of VNPs.

VNP concentrations significantly increased with increasing FSC and PRH and decreasing PRT. Variations in VNP size distributions with increasing $R T$ involved two stages. First, nucleation promoted the formation of VNPs and the VNP size increased through coagulation and condensation as RT increased. Then, VNP number concentrations decreased through coagulation. The competition between nucleation and coagulation lead to the VNP number concentrations showing rise-decay trends with increasing RT. Increasing the PDR can decrease the soot concentration and exhaust temperature, which promotes nucleation and increases the nucleation ratio. Increased PDRs decreased the partial vapor pressures of compounds involved in the formation and growth of VNPs, which suppressed nucleation, coagulation and condensation/evaporation. As a result, the VNP number concentrations reached a maximum between PDRs of $12-15$.

This work was supported by the National Natural Science Foundation of China (51006067) and the Research Fund for the Doctoral Program of Higher Education of China (20070248024).

1 Liao C M, Chio C P, Chen W Y, et al. Lung cancer risk in relation to traffic-related nano/ultrafine particle-bound PAHs exposure: A preliminary probabilistic assessment. J Hazard Mater, 2011, 190: 150-158

2 Charron A, Harrison R M. Primary particle formation from vehicle emissions during exhaust dilution in the roadside atmosphere. Atmos Environ, 2003, 37: 4109-4119

3 Seinfeld J H, Pandis S N. Atmospheric Chemistry and Physics: From Air Pollution To Climate Change. Hoboken: John Wiley \& Sons Inc, 1998. 520-524

4 Mathis U, Mohr M, Zenobi R. Effect of organic compounds on nanoparticle formation in diluted diesel exhaust. Atmos Chem Phys, 2004, 4: 609-620

5 Wong C P, Chan T L, Leung C W. Characterisation of diesel exhaust particle number and size distributions using mini-dilution tunnel and ejector-diluter measurement techniques. Atmos Environ, 2003, 37: 4435-4446

6 Cheng X B, Huang R H, Chen D L. The influence of measurement conditions on exhaust particle size distribution of direct injection diesel engine (in Chinese). Vehicle Engin, 2006, 1: 53-57

7 Zhang K M, Wexler A S. Evolution of particle number distribution near roadways: Part I. Analysis of aerosol dynamics and its implications for engine emission measurement. Atmos Environ, 2004, 38: 6643-6653

8 Fu J, Ning Z, Lu X Z. Analysis on the forming and evolution of vehicular exhaust particles (in Chinese). Environ Sci Manage, 2006, 31: 56-58

9 Fuchs N A. Mechanics of Aerosols. New York: Pergamon Press, 1964. 21

10 Doyle G J. Self-nucleation in the sulfuric acid-water system. J Chem Phys, 1961, 35: 795-799

11 Reiss J. The kinetics of phase transition in binary system. J Chem Phys, 1950, 18: 840-848

12 Roedel W. Measurement of sulfuric acid saturation vapor pressure: Implications for aerosol formation by heteromolecular nucleation. J Aerosol Sci, 1979, 10: 375-386

13 Shi J P, Harrison R M. Investigation of ultrafine particle formation during diesel exhaust dilution. Environ Sci Technol, 1999, 33: 3730-3736

14 Vouitsis E, Ntziachristos L, Samaras Z. Modeling of diesel exhaust aerosol during laboratory sampling. Atmos Environ, 2005, 39: 1335-1345

15 Li X L, Huang Z, Wang J S, et al. Characteristics of ultrafine particles emitted from a dimethyl ether (DME) engine. Chin Sci Bull. 2008, 52: 304-312

16 Li X L. Study of emission characteristics of ultrafine particles emitted from engines and variation of ultrafine particles during exhaust dilution (in Chinese). Doctoral Dissertation. Shanghai: Shanghai Jiao Tong University, 2007

17 Liu W, Zhang W G, Zhu L, et al. Characteristics of ultrafine particle from a compression-ignition engine fueled with low sulfur diesel. Chin Sci Bull, 2009, 54: 4411-4417

18 Mathis U, Ristimaki J, Mohr M. Sampling conditions for the measurement of nucleation mode particles in the exhaust of a diesel vehicle. Aerosol Sci Technol, 2004, 38: 1149-1160

Open Access This article is distributed under the terms of the Creative Commons Attribution License which permits any use, distribution, and reproduction in any medium, provided the original author(s) and source are credited. 